University of Tennessee Health Science Center UTHSC Digital Commons

Spring 4-25-2020

\title{
Survey of Client Perspective On The Use of Veterinary Telemedicine For Chronic Disease Management
}

Nathan Jay Matlock

University of Tennessee Health Science Center

Follow this and additional works at: https://dc.uthsc.edu/hiimappliedresearch

Part of the Health and Medical Administration Commons, and the Health Information Technology Commons

\section{Recommended Citation}

Matlock, Nathan Jay, "Survey of Client Perspective On The Use of Veterinary Telemedicine For Chronic Disease Management" (2020). Applied Research Projects. 72. . https://doi.org/10.21007/chp.hiim.0070 https://dc.uthsc.edu/hiimappliedresearch/72

This Research Project is brought to you for free and open access by the Department of Health Informatics and Information Management at UTHSC Digital Commons. It has been accepted for inclusion in Applied Research Projects by an authorized administrator of UTHSC Digital Commons. For more information, please contact jwelch30@uthsc.edu. 
Survey of Client Perspective On The Use of Veterinary Telemedicine For Chronic Disease Management

Nathan Matlock, PharmD

The University of Tennessee Health Science Center

Master of Health Informatics and Information Management

Advisor: Dr. Sajeesh Kumar

April 25, 2020 


\section{Acknowledgements}

I would like to express my gratitude to Dr. Sajeesh Kumar for extending his time and energy to advise me the duration of this project. I would also like to thank Sally Poston, DVM and Stephen Newby, PhD for allowing me to conduct this project at their veterinary clinics. Finally, I would like to thank my wife, Jessica Matlock, DVM, for her love and support throughout the duration of being dual enrolled in the PharmD and MHIIM programs. 


\begin{abstract}
Veterinary Telehealth is a rapidly growing sector of Veterinary Medicine. Technological advancements have allowed for vast changes in the way chronic disease states can be managed. There are many facets of telemedicine that must be researched to determine the productiveness of such technological advances. The first step in determination of implementation is that of community acceptance and likely utilization. This project's scope is to determine client perspective on the use of veterinary telemedicine for chronic disease state(s) management.
\end{abstract}


Table of Contents

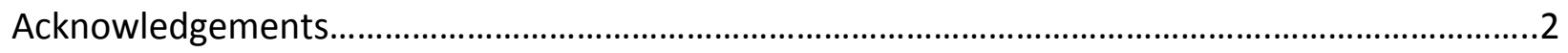

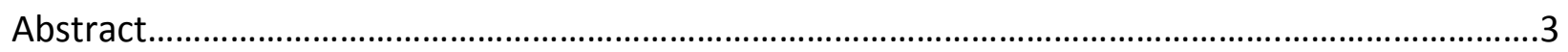

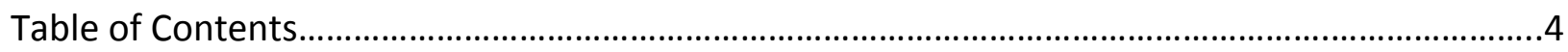

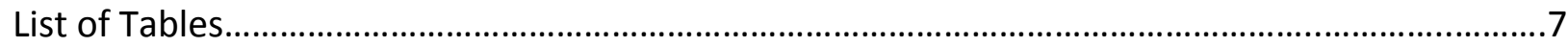

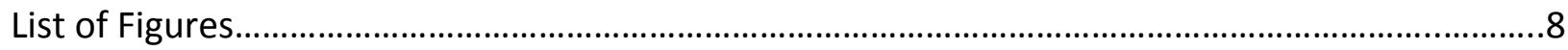

Survey of Client Perspective On the Use of Veterinary Telemedicine For Chronic Disease

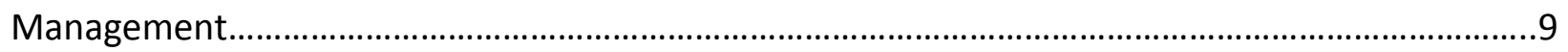

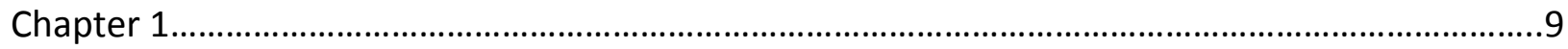

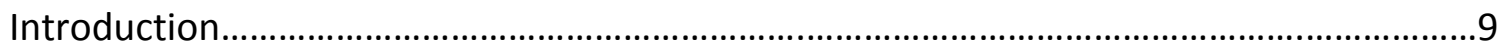

Chronic Disease State Management................................................................

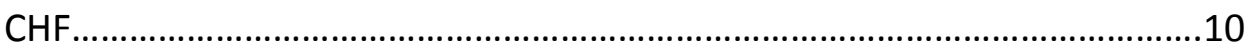

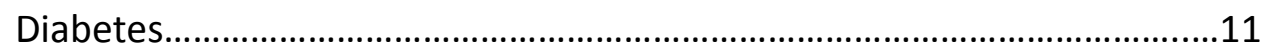

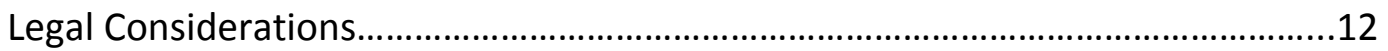

Licensing/Interstate Practice ................................................................12

Owner Confidentiality..........................................................................13

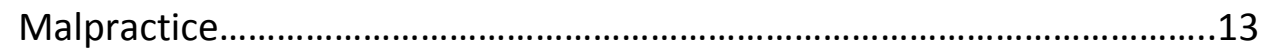

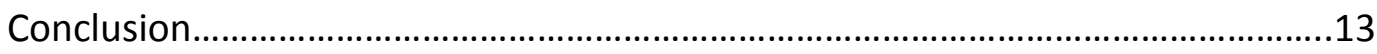

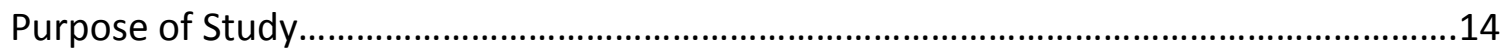

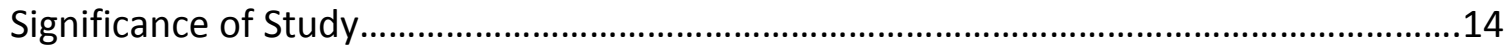

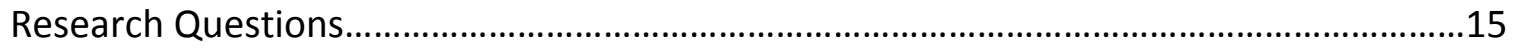

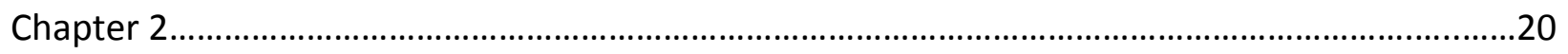

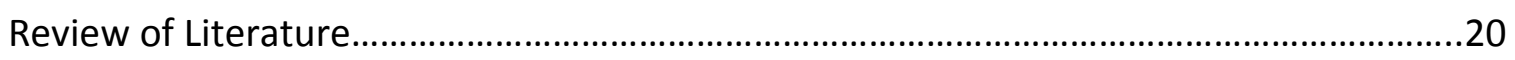

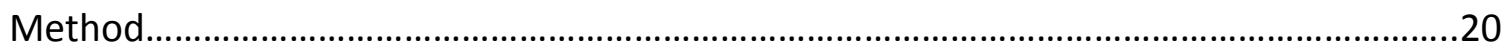

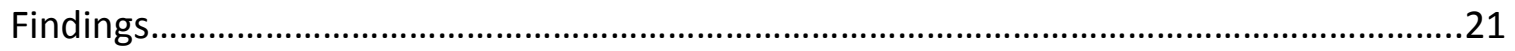

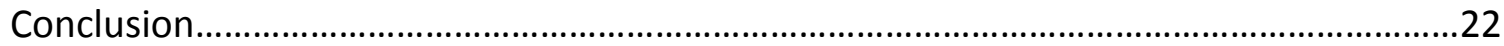

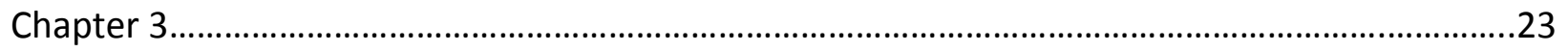




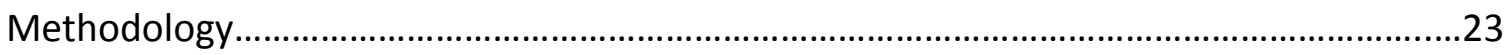

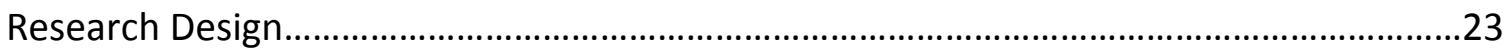

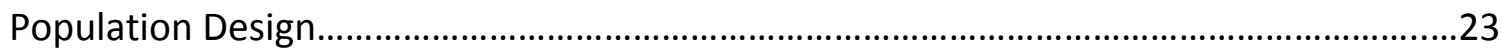

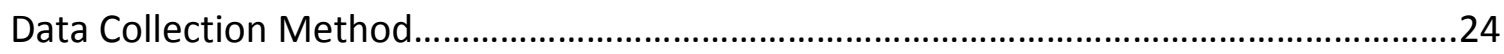

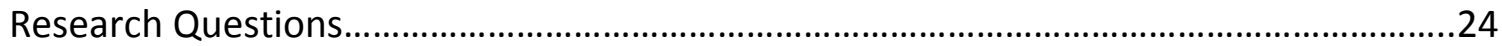

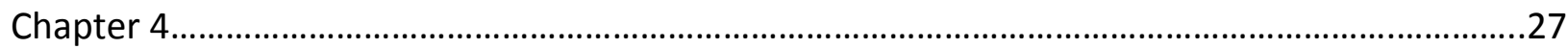

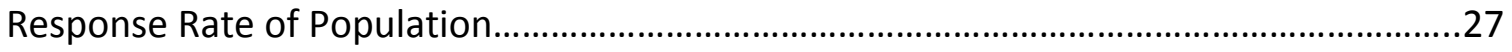

Summary of Findings...................................................................................................2

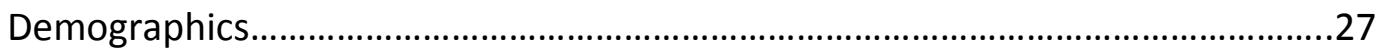

Willingness to Utilize Telemedicine Surrounding Veterinary Care..........................28

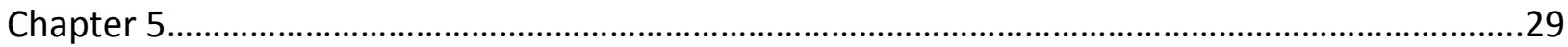

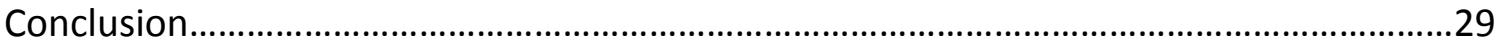

Recommendations and Limitations................................................................................30

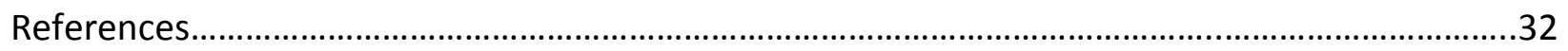

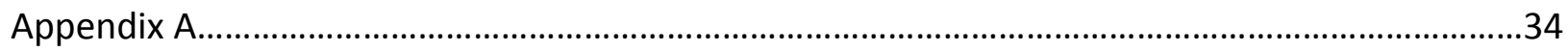

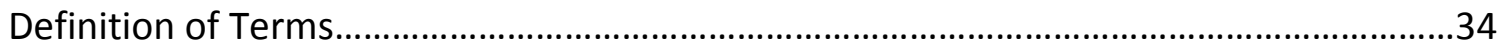

Table 1a: Review of Literature...........................................................................................35

Table 1b: Review of Literature........................................................................................

Table 2: Questionnaire Break.........................................................................................

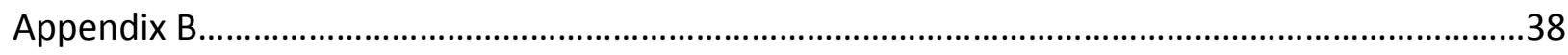

Figure 1: Review of Literature Search Results...................................................................38

Figure 2: Sample IRB Approved Consent Cover Letter.........................................................39

Figure 3: IRB Approved Survey Form Sample.....................................................................40

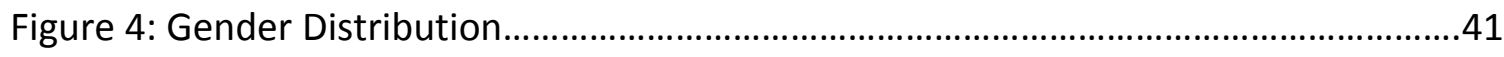

Figure 5: Age Distribution.......................................................................................

Figure 6: Clients with Accessible Internet Connection.......................................................42

Figure 7: Active Chronic Disease State Management..........................................................42 
Figure 8: Current Duration of Chronic Disease State Management..................................43

Figure 9: Aware of What Telemedicine Is? ............................................................43

Figure 10: Would Telemedicine Decrease Time Spent in Clinic?...................................44

Figure 11: Would Telemedicine Increase Improvement of Chronic Disease State Management?..................................................................44

Figure 12: Would Telemedicine Decrease Pet Stress Level?......................................45

Figure 13: Comfort in Performing Self-Management of Chronic

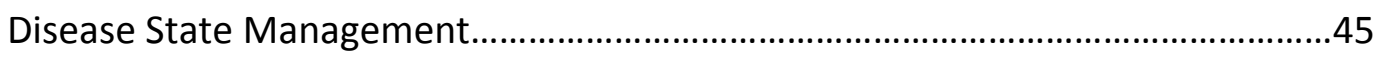

Figure 14: Does Telemedicine Decrease Relationship Between

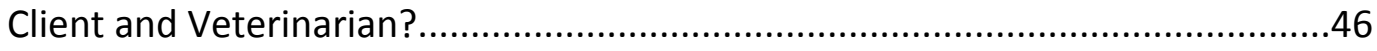


List of Tables

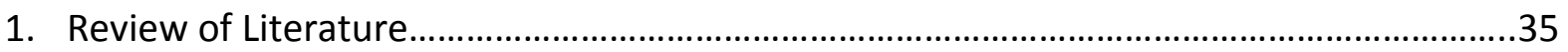

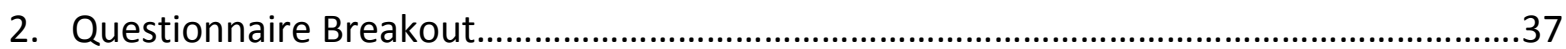




\section{List of Figures}

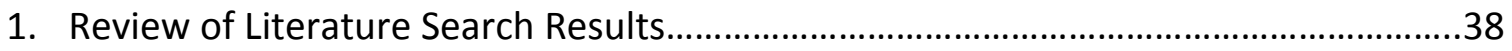

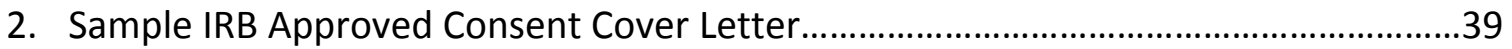

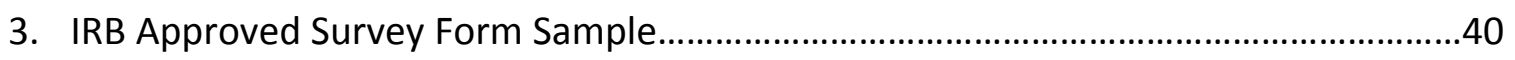

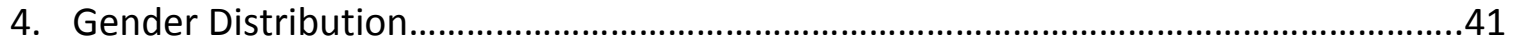

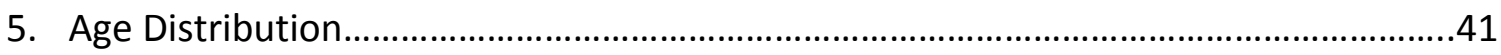

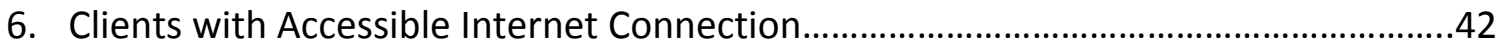

7. Active Chronic Disease State Management...............................................................42

8. Current Duration of Chronic Disease State Management............................................43

9. Aware of What Telemedicine Is? .........................................................................43

10. Would Telemedicine Increase Improvement of Chronic Disease State Management?.................................................................................44

11. Would Telemedicine Reduce Time Spent in Clinic? ..............................................44

12. Would Telemedicine Reduce Pet Stress Level?..................................................45

13. Comfort in Performing Self-Management of Chronic Disease State............................45

14. Does Telemedicine Reduce Relationship Between Client and Veterinarian?.............46 


\section{Chapter 1}

\section{Introduction}

The veterinary health care field is rapidly expanding and the overlap between it and human health care is becoming more important as populations become increasingly dense. The Public Health Department has had an interest in the field of veterinary health care for this reason for some time. The benefits of being able to monitor both human and animal health can lead to a healthier environment for all. Along with the improving the health of the community at large, there are many financial benefits that a significant number of veterinarians are failing to capitalize on, due under-utilizing veterinary telemedicine. Animal owners are also voicing their opinions on the matter and have noted the benefits their pets receive from a veterinary clinic's adoption of veterinary telemedicine.

\section{Chronic Disease State Management}

Eventually, for individuals in the populous that have companion and production animals, they must manage the chronic diseases that their animals may develop. Among the most common disease state a companion animal develops is Congestive Heart Failure (CHF) and/or Diabetes. Congestive Heart Failure and Diabetes are both disease states that must be individually managed but can also be concurrent and require more intensive chronic management. Chronic disease state management not only results in emotional distress to both the owner and animal, it also has an economic impact in the form of direct expense, as well as the time required for the owner to appropriately manage the disease state with their veterinarian. 


\section{CHF}

As an animal ages, just as their human counterparts, their hearts undergo cardiac remodeling from years of sustained use. This will eventually result in cardiomyopathy which will require years of chronic management. At Stage B or C heart failure an animal will need to begin chronic management that requires significant intervention by a licensed veterinarian (Couëtil, L., et.al. 2009). The initial treatment is composed of lifestyle and dietary modifications, and medications (Couëtil, L., et.al. 2009). An animal is typically placed on an oral diuretic, an Angiotensin Converting Enzyme Inhibitor (ACEI), Beta-blocker, pimobendan, aldosterone antagonist, along with other medications and electrolyte replacement therapies. Weekly to daily weight monitoring, in addition to respiratory and heart rate monitoring, are all required. The initiation of heart failure treatment can require an increased number of visits to the veterinarian until a stable regimen has been established. Once a regimen has been established routine follow-up visits are necessary to ensure adequate response to therapy. The use of Telemedicine cannot replace initial veterinary visits to evaluate a basic metabolic panel (BMP) at regular intervals that are utilized to determine rate of disease progression and possible electrolyte derangements. Telemedicine does offer the client, animal and veterinarian a supplement of care that can reduce patient expense and stress induced on the animal. The utilization of Telemedicine and consistent owner participation can drastically increase the level of care that their animal receives. Daily weight monitoring along with heart and respiratory rate data collection, can all be collected and transmitted to a veterinarian via telecommunications. If any of the reported parameters are outside the normal limits, the veterinarian can intervene 
prior to the animal having an acute exacerbation, which increases expense to the owner, stress on the animal and increases veterinarian daily workload.

\section{Diabetes}

Diabetes, as in humans, is an expanding concern within veterinary medicine (Behrend, E., et. al. 2018). There are numerous factors contributing to the care of an animal that has been diagnosed with diabetes. Diabetes can be a deadly disease for animals and humans alike and must be managed appropriately to prevent increased mortality and disease state exacerbations or prevent disease progression. Effective monitoring is essential for the management of diabetes in animals and humans. Diabetes requires regular monitoring of both direct and indirect methods (Behrend, E., et. al. 2018). Body weight, polyuria, polydipsia, hyperphagia are all indirect methods, while hyperglycemia, and presence of urinary ketones are direct measurements (Behrend, E., et. al. 2018). Newly diagnosed patients can require regular monitoring between every seven to fourteen days and more established patients are suggested to be have monitoring every four to twelve months (Behrend, E., et. al. 2018). Just as in CHF, the frequency of monitoring can drastically impact an owner and animal in the form of direct expense and stress related issues from chronic travel. Feline patients with diabetes are exceptionally sensitive to transportation to a veterinarian for regular management (Zoran, D.L. and Rand, J., 2013). Felines can experience what is known as stress induce hyperglycemia that can last for hours post the inducing event, which increases the difficulty of the veterinarian to accurately adjust insulin doses. This effect can cause the adjusted dose of insulin to be too high for the feline once it returns to its regular lifestyle at home (Zoran, D.L. and Rand, J., 2013). Felines are also unique in that often, Diabetes is reversible with quick and consistent 
management, which Telemedicine could easily facilitate. Many owners want to provide the best care for their animal, but are typically limited by time and financial resources, especially in more rural populations. The use of Telemedicine for chronic diabetes management can drastically reduce both concerns, allowing the owner to provide adequate care at a reasonable expense. Telemedicine would allow the veterinarian, as in $\mathrm{CHF}$, the ability to make more accurate adjustments as physiological parameters deviate from the animal's baseline values. The owner typically adjusts to the regimen and the skills needed to accurately collect physiologic data for reporting (Bloom, C.A. and Rand, J., 2014).

\section{Legal Considerations}

While there is a significant portion of Veterinarians openly welcoming the implementation and use of Telemedicine in their practices there are just as many practitioners who remain wary (Jack, D.C., 1999). There are several legal aspects that must be adequately addressed, as they were in human medicine, since the use of Telemedicine was first implemented in the 1950's by National Aeronautics and Space Administration (NASA). The use of new technology is not only convenient and opportunistic, but it can also come with professional consequences with its use.

\section{Licensing/Interstate Practice}

Currently veterinarians are required to be licensed in the state in which they practice (Jack, D.C., 1999). Telemedicine opens avenues that allow practitioners to provide medical advice to for a pet that is in a state they may not be licensed to practice. Rural areas of 
Tennessee are often boarded by several states, which could create a legal issue for a veterinarian, if they have not adequately researched their state laws.

\section{Owner Confidentiality}

One of the largest hurdles a veterinarian must overcome and educate their clients about, is that their privacy is always protected. The ability to transmit data erroneously is exceptionally easy to do with the use of telemedicine, it rests on the shoulders of the veterinarian to ensure adequate data protection for the client's comfort. Owners must be informed about the details of telemedicine use and the possible risks. The client must provide consent to participate in telemedicine utilized to treat chronic disease state(s) management.

\section{Malpractice}

There are two schools of thought on how Telemedicine impacts the veterinary standards of care. The first thought, that the use will increase the ability of practitioners to collaborate, reduce liability, implement a more comprehensive exam, and increased access to databases that facilitate an increased opportunity to obtain an accurate diagnosis. While the second thought, that the reason listed above actually increase the chances of malpractice suits due to increased client expectations with the increased ability to consult.

\section{Conclusion}

Congestive Heart Failure, Diabetes, among others are disease states that are becoming more prominent and require the time of both clients and veterinarians for education and management. Chronic disease state management is a part of life for many pet owners and the 
utilization of technology can drastically reduce the stress, time and expense that an owner must incur to give their pet a higher level of care. In 2017, RCVS reported that "the area of Telemedicine is poorly defined, rapidly evolving and it would be years before technologies reached the veterinary market." (Nelson-Pratt, A., 2018). At the current rate of implementation and debate on regulation, Veterinary Medicine is being left behind by their human counterparts. The use of Telemedicine is no longer a "wait-and-see" argument, rather it is an argument of how quickly veterinary practices across the country implement systems to meet client demand. Telemedicine can drastically change the way a veterinarian is able to provide care for their patients. While a newer approach to care, this study aims to determine client perspective on the use of Telemedicine, in three rural Tennessee veterinary clinics, for their pet's current or future chronic disease state management.

\section{Purpose of the Study}

Given the rapid progression of utilization of technology within the field of Veterinary Medicine it is important to understand how receptive clients would be to the use of telemedicine for the management of their pet's chronic disease state(s). It is ultimately the client's decision to participate in the use of telemedicine and it is imperative that it is understood what constraints may be present prior to implementing telemedicine services.

\section{Significance of Study}

Telemedicine technologies can significantly improve disease state management, especially in more rural areas. Telemedicine in rural Appalachia has the potential to alleviate the "care-gap" present for chronic disease state(s) management in veterinary medicine. 


\section{Research Questions}

The overall goal of this study was to determine client perspective on the use of veterinary telemedicine for chronic disease state(s) management. The questions listed below were generated with this idea in mind. There is a total of sixteen questions with three of those being demographic in nature and the remaining thirteen addressing current pet disease state(s), client comfortableness managing the disease state(s), and opinions about the use of telemedicine surrounding their pet's care. The questions selected for the survey are as follows:

1.) Are you male, female, or identify as other?
a. Male
b. Female
c. Other

2.) Age
a. Under 23
b. $24-42$
C. 43-54
d. 55-73
e. Over 74

3.) Do you have regular access to the internet?
a. Yes
b. No 
4.) Do you or someone you know have an animal that requires management of a chronic disease state (e.g. Diabetes or Heart Failure)?
a. Yes
b. No

5.) If so, what disease state are they being treated for?
a. Diabetes
b. Congestive Heart Failure
c. Other - Please List:

6.) How long has your pet been treated for their long-term disease state?
a. Less than 1 year
b. 1-5 years
c. Greater than 5 years
d. N/A

7.) Are your pet(s) with long-term disease(s) seen regularly by a veterinarian to manage their long-term disease?
a. Yes - regular management - CKD, DM, CHF, Thyroid - Every 6 months
b. No - only when disease state flares

8.) Are you aware of what telemedicine/telehealth is?
a. Yes
b. No 
9.) Excluding call to schedule an appointment, have you or someone you know ever used an electronic device (phone, computer, etc.) to contact their veterinarian regarding their pet's long-term care?
a. Yes
b. No

10.) Do you feel that the use of telemedicine/telehealth could improve the long-term care of your pet?
a. Strongly Agree
b. Agree
c. Neutral
d. Disagree
e. Strongly Disagree

11.) Do you feel that the use of telemedicine could reduce the time spent waiting in the clinic for long-term disease state management?
a. Strongly Agree
b. Agree
c. Neutral
d. Disagree
e. Strongly Disagree 
12.) Do you feel that your pet's stress level would be lowered by reducing the number of visits to the veterinary office for long-term disease management?
a. Strongly Agree
b. Agree
c. Neutral
d. Disagree
e. Strongly Disagree

13.) If provided with proper management techniques for a disease state, how comfortable would you feel monitoring and reporting the results to your veterinarian via electronic communication?
a. Very Comfortable
b. Comfortable
c. Neutral
d. Uncomfortable
e. Very Uncomfortable 
14.) Do you feel that the use of telemedicine/telehealth to monitor and manage longterm disease state would decrease the relationship you and your pet have with the veterinarian?
a. Strongly Agree
b. Agree
c. Neutral
d. Disagree
e. Strongly Disagree

15.) Would you like more information on telemedicine/telehealth?
a. Yes
b. No

16.) Do you have any additional comments or suggestions? Please write them below. 


\section{Chapter 2}

\section{Literature review of Veterinary Telemedicine and its use for chronic disease state(s) management}

\section{Introduction}

There are multiple articles that have been published on the topic of telehealth and its utilization in the field of Veterinary Medicine. Many of the articles published center their focus on if the implementation is correct for the field and what proper use would be visualized as, protocols on how to implement a telehealth system into a practice setting and the regulatory aspects of utilization. While there is limited information available on the above topics, there is no data available that addresses the issue of client perspective on the utilization of Veterinary Telemedicine for the management of their pet's chronic disease state (e.g. Congestive Heart Failure and Diabetes.)

\section{Method}

The literature articles that were utilized to expand on the utility of telemedicine utilization in chronic disease state management for animals were obtained by searching PubMed journal database. The search terms utilized were "Veterinary Telemedicine", in addition to the terms "Veterinary Telemedicine AND chronic disease management", "Telemedicine AND heart failure AND diabetes", "Veterinary Telemedicine AND Legal", "Veterinary Telemedicine AND heart failure", Veterinary Telemedicine AND diabetes", "Veterinary Congestive Heart Failure Treatment Guidelines", "Veterinary Diabetes Treatment Guidelines", "Telemedicine AND Heart Failure", "Telemedicine and Diabetes". The first search, utilizing the terms "Veterinary Telemedicine", produced a possible ninety journal articles. Of these ninety articles, nineteen articles were selected for possible inclusion in this paper. The 
second search, utilizing the terms "Veterinary Telemedicine AND chronic disease

management", produced a possible one article, which was not included in this paper. The third search, utilizing the terms "Telemedicine AND heart failure AND diabetes" yielded one-hundred and nine possible results with none being relevant to this paper. The fourth search, utilizing the terms "Veterinary Telemedicine AND Legal" produced a possible two articles which were included in this paper. The fifth search, utilizing the terms "Veterinary Telemedicine AND heart failure" produced a possible article that was not included in this paper. The sixth search, utilizing the terms "Veterinary Telemedicine AND diabetes" produced a possible three articles of which none were used in this paper. The seventh search, utilizing the terms "Veterinary Congestive Heart Failure Treatment Guidelines" produced a possible ten articles and one was included in this paper. The eighth search, utilizing the terms "Veterinary Diabetes Treatment Guidelines" produced a possible fourteen articles of which one was used in this paper. The ninth search, utilizing the terms "Telemedicine AND Heart Failure" resulted in nine-hundred and seventy-five articles and none were used in this paper. The tenth search, utilizing the terms "Telemedicine and Diabetes" produced one-thousand nine-hundred and fifteen articles of which one was used in this paper. There were many articles regarding how telemedicine was perceived and the likelihood of use, but true outcome comparison studies were lacking.

\section{Findings}

The database search returned twenty-one articles that were utilized in this is survey. Of the twenty-nine articles returned, none could be classified as research studies. These articles provided information such as to how to utilize Telemedicine in veterinary radiology, the future usefulness of telemedicine in the veterinary field, how to choose and implement a 
Telemedicine system within a veterinary clinic, possible veterinary specialty uses of telemedicine, legal aspects of telemedicine utilization, and debates among professionals on how telemedicine should be utilized in the veterinarian's practice. The major limitation to studies that surround Veterinary Telemedicine are that there are very limited data on the subject, and none approached the client's personal view of Telemedicine and its utilization. A more detailed expansion on each study utilized for this study can be reviewed in Table 1a and Table $1 b$ on page 35 and 36.

\section{Conclusion}

This literature review indicates that more research is needed to show how a rural population perceives the usefulness of Telemedicine in the setting of a rural veterinary clinic. There are review articles that address if implementation is correct for the field and what proper use would be visualized as, protocols on how to implement a telehealth system into a practice setting and the regulatory aspects of utilization. Telemedicine is a unique method of delivering medical treatment for those animal owners that are in rural areas, have limited funds or time. Telemedicine can and will help push veterinary care into the more rural areas where it is not always cost effective to treat an animal with a chronic disease state. Initially, there must be studies that are completed to determine the client's perspective of telemedicine use for chronic disease state management in the rural areas to assess viability of such technology. 


\section{Chapter 3}

\section{Methodology}

This study utilized a client survey to determine the acceptance of utilizing telemedicine within three veterinary clinics in rural East Tennessee. The clinics involved in this study were Animal Medical Center in Cleveland, TN; Clinton Animal Hospital and Norris Veterinary Animal Hospital in Clinton, TN. The details outlined in the chapter will serve to present a clear picture of research design, implementation and analyzation of the survey.

\section{Research Design}

The survey method of the descriptive research method was utilized to gather information from participants. This method of data collection was deemed to be the most appropriate to be able to describe the client's rationale on the utilization of telemedicine for specific aspects of veterinary care. The utilization of a survey afforded the client a certain level of privacy for a more complete opinion. The survey was written in such a way that the questions were direct, simplistic to understand with minimal interjection from principal investigator or staff assisting with survey administration.

\section{Population Design}

The selected population for this study was composed of individuals over the age of 18 years of age and had a basic comprehension level of the English language. It was also determined that the population would be three rural veterinary clinics in Eastern Tennessee. 


\section{Data Collection Method}

The instrument utilized for data collection was a sixteen question, double sided, questionnaire. Questions were designed to be multiple choice with one open-ended question. There were three questions directed toward patient demographics (e.g. sex, age, and access to internet), while the remaining thirteen questions were written to capture information relating to a pet's current health state and client opinions toward the utilization of telemedicine in the care of their pet's chronic disease state(s) management.

\section{Research Questions}

This research was conducted to determine how receptive a rural population within Eastern Tennessee would be to toward their veterinarian utilizing telemedicine adjunctively to manage their pets with a chronic disease state(s). The questions that were utilized in the survey were generated based on similar studies that had been previously conducted on the use of telemedicine implementation in the literature. Rationale for the inclusion of each question utilized in the survey is listed.

1.) Are you male, female, or identify as other?

Rationale: Demographic Impact

2.) Age?

Rationale: Demographic Impact

3.) Do you have regular access to the internet?

Rationale: Demographic Impact 
4.) Do you or someone you know have an animal that requires management of a chronic disease state (e.g. Diabetes or Heart Failure)?

Rationale: Pet health status classification

5.) If so, what disease state are they being treated for?

Rationale: Narrow pet health status classification

6.) How long has you pet been treated for their long-term disease state?

Rationale: Determine how long a client may have been managing their pet(s) to date

7.) Are your pet(s) with long-term disease(s) seen regularly by a veterinarian to manage their long-term disease?

Rationale: Determine commitment to pet's health status

8.) Are you aware of what telemedicine/telehealth is?

Rationale: Demographic Impact

9.) Excluding calls to schedule an appointment, have you or someone you know ever used an electronic device (phone, computer, etc.) to contact their veterinarian regarding their pet's long-term care?

Rationale: Determine existing comfort with electronic devices

10.) Do you feel that the use of telemedicine/telehealth could improve the long-term care of your pet?

Rationale: Willingness to utilize telemedicine

11.) Do you feel that the use of telemedicine could reduce the time spent waiting in the clinic for long-term disease state management?

Rationale: Client opinion on usefulness of telemedicine 
12.) Do you feel that your pet's stress level would be lowered by reducing the number of visits to the veterinary office for long-term disease management? Rationale: Client opinion on usefulness of telemedicine

13.) If provided with proper management techniques for a disease state, how comfortable would you feel monitoring and reporting the results to your veterinarian via electronic communication?

Rationale: Client comfort level with being more hands on with care

14.) Do you feel that the use of telemedicine/telehealth to monitor and manage longterm disease states would decrease the relationship you and your pet have with the veterinarian?

Rationale: Perspective on technology altering personal relationships

15.) Would you like more information on telemedicine/telehealth?

Rationale: Client openness to a new process or procedure

16.) Do you have any additional comments or suggestions? Please write them below. Rationale: Capture client opinions that may have not been included in the multiplechoice portion of survey. 


\section{Chapter 4}

\section{Response Rate of Population}

The study was conducted over a sixty-day period. During this time period clients at each office were asked if they would like to participate Monday through Saturday, during the operating hours of each clinic. The clinics were closed on Sunday; thus, no surveys were completed. During this sixty-day period, 75 individuals were asked for their participation. Of the 75 asked for their participation, 64 agreed to complete the survey. If a client was asked to complete a survey the survey had "NO" written and filed with the completed surveys. The response rate during this study was $85.33 \%$.

\section{Summary of Findings}

\section{Demographics}

The results that were obtained during this study surrounding the use of Telemedicine for their pet's chronic disease state(s) management are unique, but at the same time representative of each rural population. Within this sampling, $15.6 \%$ of the population identified as male, $82.8 \%$ identified as female and $1.6 \%$ identified as "other" (Figure 4.). The more rural clinics, Norris Veterinary Animal Hospital and Clinton Animal Hospital had no participants under 23 years of age. 24 to 73 years of age composed $98.4 \%$ of the sample population (Figure 5.). The largest age bracket participating in the survey was $55-73$ years of age, with $32.8 \%$ of the population (Figure 5.). When asked "Are you aware of what telemedicine/telehealth is?" $42.9 \%$ of the population responded "Yes", while 57.1\% responded "No" (Figure 9.). 


\section{Willingness to Utilize Telemedicine Surrounding Veterinary Care}

The overall goal of this study was to determine client perspective on utilizing Telemedicine for their pet's chronic disease state(s) management. The results of the survey indicate that when asked "Do you feel that the use of Telemedicine/Telehealth could improve the long-term care of your pet?", $45.7 \%$ of respondents cited that they "strongly agree" or "agree" that Telemedicine/Telehealth could improve their pet's long-term health care, while $11.9 \%$ of the respondents felt that their pet's health care would not be improved with the use of Telemedicine/Telehealth (Figure 11.). It was also in question if the clients would feel comfortable monitoring and reporting health care data to their veterinarian via Telemedicine/Telehealth. When asked "If provided with proper management techniques for a disease state, how comfortable would you feel monitoring and reporting the results to your veterinarian via electronic communication?", 50.8\% reported that they would be "very comfortable" or "comfortable" with such methods, while $15.3 \%$ reported that they would not be comfortable (Figure 13.). When clients were asked "Do you feel that the use of Telemedicine/Telehealth to monitor and manage long-term disease states would decrease the relationship you and your pet have with the Veterinarian?" $47.4 \%$ thought the use of Telemedicine/Telehealth would decrease the relationship, while $53.6 \%$ felt it would not have negative implications on the relationship (Figure 14.). 


\section{Chapter 5}

\section{Conclusion}

This study aimed to make an initial determination of client perspective of utilizing Telemedicine/Telehealth for a pet's chronic disease state(s) management, in three rural settings in Eastern Tennessee. The results indicate that the rural populations selected would be receptive to the utilization of Telemedicine/Telehealth, if their veterinarian began to utilize such technologies. The study also indicates that clients feel their pet's stress level would be decreased by less frequent visits to the clinic and would result in far less time spent in the clinic with their pet. An interesting concern drawn from this survey was that clients felt that Telemedicine would have a negative effect on their and their pet's relationship with their veterinarian. Currently, across the clinics, only $52.9 \%$ of clients have their pets with long-term disease states regularly managed by a veterinarian, indicating that the other $47.1 \%$ have their pets seen once the pet is in an exacerbated state. This not only results in lost time for the client and distress to the pet, but also has significant economical impact for the client and veterinary clinic.

In conclusion, this study provided insight to how clients, in select rural settings, perceive the use of Telemedicine/Telehealth surrounding the care of their pets. It is shown that these three veterinary clinics in rural East Tennessee are willing to utilize Telemedicine/Telehealth for the benefit of their pet through the duration of their management of long-term chronic disease states. 


\section{Recommendations and Limitations}

Based on the data collected from this survey it is a reasonable assumption that individuals located in a rural setting would find benefit in the utilization of Telemedicine/Telehealth in treating their pets with long-term chronic disease state(s). This information provides the veterinary and telehealth communities with possible revenue and improved client adherence given that this territory that has been largely left unexplored. While many clients did have interest in the utilization of Telemedicine/Telehealth for their pet's care, they did have reservations about what the use of technologies and implications they would have on their relationship with their veterinarian. There is no easy solution to mitigate emotional stressors, but this could be an opportune situation to build client trust with the increased ability to reach them at a more personal level.

Limitations of this study included, unanswered questions, possible difficulty understanding the scope of the question(s), possible fatigue answering survey questions, duration of the survey. There were multiple surveys that were taken and not fully completed. Given that $57.1 \%$ of the clients did not know what Telemedicine/Telehealth was, the questions themselves may have been difficult to answer. Some of the clients could have been presenting to the clinic with an acutely ill pet, resulting in fatigue answering the survey questions. An extended survey period would generate more participants, thus more valuable data. Another limitation is that, not every client was asked to participate in the survey. Receptionists asked clients to complete survey at slower intervals in the day. If this survey was conducted again, it would be advisable to have each patient asked upon arrival. Those patients arriving in a busy portion of a day may be able to provide an insight than those casually waiting do. Future 
studies could take this study and expand to a more rural setting and focus questions more toward the client/veterinarian relationship. In addition, a more thorough study could be conducted to determine client education levels, and abilities to utilized telecommunication methods. 


\section{References}

Behrend, E., Holford, A., Lathan, P., Rucinsky, R., \& Schulman, R. (2018). 2018 AAHA Diabetes Management Guidelines for Dogs and Cats. American Animal Hospital Association, 54(1), 1-21. https://doi.org/10.5326/JAAHA-MS-6822

Bloom, C. A., \& Rand, J. (2014). Feline Diabetes Mellitus: Clinical use of long-acting glargine and detemir. Journal of Feline Medicine and Surgery, 16, 205-215. https://doi.org/10.1177/1098612X14523187

Cook, A. K. (2012). Monitoring Methods for Dogs and Cats with Diabetes Mellitus. Journal of Diabetes Science and Technology, 6(3), 491-495.

Couëtil, L., Hoffman, A., Hodgson, J., Buechner-Maxwell, V., Viel, L., Wood, J., \& Lavoie, J.-P. (2009). Guidelines for the Diagnosis and Treatment of Canine Chronic Valvular Heart Disease. J Vet Intern Med, 23, 1142-1150. https://doi.org/10.1111/i.1939$\underline{1676.2009 .0392 . x}$

Gyles, C. (2019). Veterinary Telemedicine. CVJ, 60(February), 119-121.

Hess, L. (2017). Telemedicine: The Future of Veterinary Practice. Journal of Avian Medicine and Surgery, 31(2), 165-171.

Jack, D. C. (1999). The legal implications of veterinary telemedicine and telecare. Journal of Telemedicine and Telecare, 5(1), 80-84.

Larkin, M. (2015). AVMA panel to scrutinize telemedicine. JAVMA News, 247(9), 987-988.

Mars, M., \& Auer, R. E. J. (2006). Telemedicine in veterinary practice. S.Afr.Vet.Ver., 77(2), 7578.

Nack, R., \& Declue, A. E. (2014). In cats with newly diagnosed diabetes mellitus, use of a neareuglycemic management paradigm improves remission rate over a traditional paradigm. Veterinary Quarterly, 34(3), 132-136. https://doi.org/10.1080/01652176.2014.924057

Nelson-pratt, A. (2018). Telemedicine debate is taking far too long. Vet Record, (December), 663. https://doi.org/10.1136/vr.k5073

Oteet, B. R. A. P. (2008). Veterinary Teleradiology. Veterinary Radiology \& Ultrasound, 49(1), 33-36. https://doi.org/10.1111/j.1740-8261.2007.00331.x

Papageorges, M. (2001). Clincal Techniques in Small Animal Practice. Clinical Techniques in Small Animal Practice, 16(2), 87-89. https://doi.org/10.1053/svms.2001.26224 
Papageorges, M., \& Hebert, P. (2001). Telemedicine Using Standard Internet Technologies (Telemedicine for less than $\$ 1,000)$. Clinical Techniques in Small Animal Practice, 16(2), 102-106. https://doi.org/10.1053/svms.2001.26227

Papageorges, M., \& Hebert, P. (2001). Choosing Your Telemedicine System. Clinical Techniques in Small Animal Practice, 16(2), 107-110. https://doi.org/10.1053/svms.2001.26228

Papageorges, M., Hanson, J., Girard, E., Leveille, R., Hebert, P., Latouche, J., \& Menard, M. (2001). How to Make Telemedicine Work. Clinical Techniques in Small Animal Practice, 16(2), 111-114. https://doi.org/10.1053/svms.2001.26230

Papageorges, M., \& Hebert, P. (2001). Other Telemedicine Applications. Clinical Techniques in Small Animal Practice, 16(2), 125-126. https://doi.org/10.1053/svms.2001.26236

Pathak, A.; Kumar, D. (2017). Telehealth in India : helping to achieve health for all. Veterinart Record, 180, 572-573. https://doi.org/10.1136/vr.j2219

Peterson, M.E.; Eirmann, L. (2014). Dietary Management of Feline Endocrine Disease. Vet Clin Small Animal, 44, 775-788. https://doi.org/10.1016/j/cvsm.2014.03.005

Roomp, K.; Rand, J. (2013). Management of Diabetic Cats with Long-acting Insulin. Vet Clin Small Animal, 43, 251-266. https://doi.org/10.1016/j.cvsm.2012.12.005

Zoran, D. L., \& Rand, J. S. (2013). The Role of Diet in the Prevention and Management of Feline Diabetes. Vet Clin Small Animal, 43, 233-243. https://doi.org/10.1016/i.cvsm.2012.11.004 


\section{Appendix A}

\section{Definition of Terms}

Telemedicine - to deliver of health care, health education, and health information services via remote technologies.

Telehealth - the use of electronic information and telecommunication technologies to support long-distance clinical health care, patient and professional health-related education, public health and health administration.

$\mathrm{CHF}$ - a chronic progressive condition that affects the pumping power of the heart muscles.

Diabetes - condition in which the body does not properly process food for use as energy.

Malpractice - occurs when a hospital, doctor or other health care professional, through negligent act or omission, causes an injury to a patient. 
Table 1a: Review of Literature

\begin{tabular}{|c|c|c|c|}
\hline Article Title and DOI & Year & Journal & Topic \\
\hline $\begin{array}{l}2018 \text { AAHA Diabetes } \\
\text { Management Guidelines } \\
\text { for Dogs and Cats } \\
\text { DOI: } 10.5326 / J A A H A-M S- \\
6822\end{array}$ & 2018 & $\begin{array}{l}\text { Veterinary Practice } \\
\text { Guidelines }\end{array}$ & $\begin{array}{l}\text { Diabetes } \\
\text { Management for } \\
\text { Dogs and Cats }\end{array}$ \\
\hline $\begin{array}{l}\text { Feline Diabetes Mellitus: } \\
\text { Clinical use of long-acting } \\
\text { glargine and determir } \\
\text { DOI: } 10.1177 / 1098612- \\
\text { X14523187 }\end{array}$ & 2014 & $\begin{array}{l}\text { Journal of Feline } \\
\text { Medicine and } \\
\text { Surgery }\end{array}$ & $\begin{array}{l}\text { Feline Diabetes } \\
\text { Mellitus }\end{array}$ \\
\hline $\begin{array}{l}\text { Monitoring Methods for } \\
\text { Dogs and Cats with } \\
\text { Diabetes Mellitus } \\
\text { DOI:10.1177/1932296812- } \\
00600302\end{array}$ & 2012 & $\begin{array}{l}\text { Journal of Diabetes } \\
\text { Technology Society }\end{array}$ & $\begin{array}{l}\text { Monitoring } \\
\text { methods for dogs } \\
\text { and cats with } \\
\text { diabetes mellitus }\end{array}$ \\
\hline $\begin{array}{l}\text { Guidelines for the } \\
\text { Diagnosis and Treatment } \\
\text { of Canine Chronic Valvular } \\
\text { Heart Disease } \\
\text { DOI: } 10.1111 / \text { j.1939- } \\
\text { 1676.2009.0392.x }\end{array}$ & 2009 & $\begin{array}{l}\text { Journal of Veterinary } \\
\text { Internal Medicine }\end{array}$ & $\begin{array}{l}\text { Guidelines for } \\
\text { Diagnosis and } \\
\text { Treatment of } \\
\text { Canine Chronic } \\
\text { Valvular Heart } \\
\text { Disease }\end{array}$ \\
\hline Veterinary Telemedicine & 2019 & CVMA & $\begin{array}{l}\text { Editorial } \\
\text { Statement }\end{array}$ \\
\hline $\begin{array}{l}\text { Telemedicine: The Future } \\
\text { of Veterinary Practice } \\
\text { DOI:10.1647/1082-6742- } \\
\text { 31.2.165 }\end{array}$ & 2017 & $\begin{array}{l}\text { Journal of Avian } \\
\text { Medicine and } \\
\text { Surgery }\end{array}$ & $\begin{array}{l}\text { Editorial } \\
\text { Statement }\end{array}$ \\
\hline $\begin{array}{l}\text { The legal implications of } \\
\text { veterinary telemedicine } \\
\text { and telecare. } \\
\text { DOI: } 10.1258 / 135763399- \\
1932685\end{array}$ & 1999 & $\begin{array}{l}\text { Journal of } \\
\text { Telemedicine and } \\
\text { Telecare }\end{array}$ & $\begin{array}{l}\text { Legal implications } \\
\text { of veterinary } \\
\text { telemedicine and } \\
\text { telecare }\end{array}$ \\
\hline $\begin{array}{l}\text { AVMA panel to scrutinize } \\
\text { telemedicine }\end{array}$ & 2015 & JAVMA & $\begin{array}{l}\text { Editorial } \\
\text { Statement }\end{array}$ \\
\hline $\begin{array}{l}\text { Telemedicine in veterinary } \\
\text { practice } \\
\text { DOI: } 10.4102 / \text { jsava.v77- } \\
\text { i2.348 }\end{array}$ & 2006 & $\begin{array}{l}\text { Journal of the South } \\
\text { African Veterinary } \\
\text { Association }\end{array}$ & Literature Review \\
\hline $\begin{array}{l}\text { Telemedicine debate is } \\
\text { taking far too long } \\
\text { DOI: } 10.1136 / \mathrm{vr} . \mathrm{k} 0573\end{array}$ & 2018 & Vet Record & $\begin{array}{l}\text { Editorial } \\
\text { Statement }\end{array}$ \\
\hline
\end{tabular}


Table 1b: Review of Literature

\begin{tabular}{|c|c|c|c|}
\hline Article Title and DOI & Year & Journal & Topic \\
\hline $\begin{array}{l}\text { Veterinary } \\
\text { Teleradiology }\end{array}$ & 2008 & $\begin{array}{l}\text { Veterinary Radiology } \\
\text { and Ultrasound }\end{array}$ & $\begin{array}{l}\text { Applications and } \\
\text { Legal considerations }\end{array}$ \\
\hline $\begin{array}{l}\text { Introduction } \\
\text { DOI: } \\
10.1053 / \text { svms.2001.26- } \\
224\end{array}$ & 2001 & $\begin{array}{l}\text { Clinical Techniques } \\
\text { in Small Animal } \\
\text { Practice }\end{array}$ & $\begin{array}{l}\text { Time vs. Money and } \\
\text { Risk and Vision of } \\
\text { telemedicine in the } \\
\text { Veterinary clinic }\end{array}$ \\
\hline $\begin{array}{l}\text { How to Make } \\
\text { Telemedicine Work } \\
\text { DOI: } \\
10.1053 / \text { svms.200- } \\
1.26230\end{array}$ & 2001 & $\begin{array}{l}\text { Clinical Techniques } \\
\text { in Small Animal } \\
\text { Practice }\end{array}$ & $\begin{array}{l}\text { Initiation and } \\
\text { training on } \\
\text { implemented } \\
\text { telemedicine system }\end{array}$ \\
\hline $\begin{array}{l}\text { Telemedicine Using } \\
\text { Standard Intenet } \\
\text { Technologies } \\
\text { DOI: } 10.1053 / \text { svms.20- } \\
01.26227\end{array}$ & 2001 & $\begin{array}{l}\text { Clinical Techniques } \\
\text { in Small Animal } \\
\text { Practice }\end{array}$ & $\begin{array}{l}\text { Equipment needed } \\
\text { and utilization of } \\
\text { standard internet } \\
\text { equipment in } \\
\text { veterinary } \\
\text { telemedicine }\end{array}$ \\
\hline $\begin{array}{l}\text { Other Telemedicine } \\
\text { Applications } \\
\text { DOI: } 10.1053 / \text { svms.20- } \\
01.26236\end{array}$ & 2001 & $\begin{array}{l}\text { Clinical Techniques } \\
\text { in Small Animal } \\
\text { Practice }\end{array}$ & $\begin{array}{l}\text { Different sectors } \\
\text { within veterinary } \\
\text { practice that can } \\
\text { utilize telemedicine } \\
\text { other than small } \\
\text { animal clinic }\end{array}$ \\
\hline $\begin{array}{l}\text { Choosing Your } \\
\text { Telemedicine System } \\
\text { DOI: } 10.1053 / \text { svms.20- } \\
01.26228\end{array}$ & 2001 & $\begin{array}{l}\text { Clinical Techniques } \\
\text { in Small Animal } \\
\text { Practice }\end{array}$ & $\begin{array}{l}\text { Advice on how to } \\
\text { choose a proper } \\
\text { telemedicine system }\end{array}$ \\
\hline
\end{tabular}


Table 2: Questionnaire Breakout

\begin{tabular}{|c|c|c|c|c|c|}
\hline Survey Question & Response & Norris Veterinary Animal Hospital & Clinton Animal Hospital & Animal Medical Center & Total \\
\hline 1: Are you male, female or identify as other? & \begin{tabular}{|l} 
Male \\
Female \\
Other
\end{tabular} & $\begin{array}{c}4(26.6 \%) \\
11(73.3 \%)\end{array}$ & $\begin{array}{c}4(17.4 \%) \\
18(78.2 \%) \\
1(4.3 \%)\end{array}$ & $\begin{array}{c}2(7.7 \%) \\
24(92.3 \%)\end{array}$ & \begin{tabular}{|c|}
$10(15.6 \%)$ \\
$53(82.8 \%)$ \\
$1(1.6 \%)$
\end{tabular} \\
\hline 2: Age? & $\begin{array}{l}\text { Under } 23 \\
24-42 \\
43-54 \\
55-73 \\
\text { Over } 74\end{array}$ & $\begin{array}{l}7(46.7 \%) \\
3(20 \%) \\
5(33.3 \%)\end{array}$ & $\begin{array}{c}2(8.7 \%) \\
8(34.8 \%) \\
5(21.7 \%) \\
8(34.8 \%)\end{array}$ & $\begin{array}{l}4(15.4 \%) \\
4(15.4 \%) \\
4(15.4 \%) \\
13(50 \%) \\
1(3.8 \%)\end{array}$ & $\begin{array}{c}13(20.3 \%) \\
15(23.4 \%) \\
14(21.9 \%) \\
21(32.8 \%) \\
1(1.6 \%)\end{array}$ \\
\hline $\begin{array}{l}\text { 4: Do you or someone you know have an animal that requires management of a chronic } \\
\text { disease state (e.g. Diabetes or Heart Failure)? }\end{array}$ & $\begin{array}{l}\text { Yes } \\
\text { No }\end{array}$ & $\begin{array}{c}3(20 \%) \\
12(80 \%)\end{array}$ & $\begin{array}{l}4(17.4 \%) \\
1982.6 \%)\end{array}$ & $\begin{array}{c}4(15.4 \%) \\
22(84.6 \%)\end{array}$ & $\begin{array}{l}11(17.2 \%) \\
53(82.8 \%) \\
\end{array}$ \\
\hline 5: If so, What disease state are they being treated for? & $\begin{array}{l}\text { Diabetes } \\
\text { Congestive Heart Failure } \\
\text { Other }\end{array}$ & $\begin{array}{l}1(33.3 \%) \\
2(66.6 \%)\end{array}$ & $\begin{array}{c}1(16.7 \%) \\
2(33.3 \%) \\
3(50 \%)\end{array}$ & $\begin{array}{l}2(50 \%) \\
2(50 \%)\end{array}$ & $\begin{array}{l}4(30.8 \%) \\
2(15.4 \%) \\
7(53.8 \%) \\
\end{array}$ \\
\hline 6: How long has your pet been treated for their long-term disease state? & $\begin{array}{l}\text { Less than } 1 \text { year } \\
1-5 \text { years } \\
\text { Greater than } 5 \text { years } \\
\text { N/A }\end{array}$ & $\begin{array}{l}2(16.7 \%) \\
10(83.3 \%)\end{array}$ & $\begin{array}{c}4(25 \%) \\
1(6.7 \%) \\
11(73.3 \%)\end{array}$ & $\begin{array}{l}2(9.5 \%) \\
1(4.8 \%) \\
18(85.7 \%)\end{array}$ & $\begin{array}{c}2(4.1 \%) \\
7(14.3 \%) \\
1(2 \%) \\
39(79.6 \%)\end{array}$ \\
\hline $\begin{array}{l}\text { 7: Are your pet(s) with long-term disease(s) seen regularly by a veterinarian to manage their } \\
\text { long-term disease? }\end{array}$ & $\begin{array}{l}\text { Yes } \\
\text { No }\end{array}$ & $\begin{array}{l}2(66.6 \%) \\
1(33.3 \%)\end{array}$ & $\begin{array}{l}5(55.6 \%) \\
4(44.4 \%)\end{array}$ & $\begin{array}{l}2(40 \%) \\
3(60 \%)\end{array}$ & $\begin{array}{l}9(52.9 \%) \\
8(47.1 \%) \\
\end{array}$ \\
\hline 8: Are you aware of what telemedicine/telehealth is? & $\begin{array}{l}\text { Yes } \\
\text { No }\end{array}$ & $\begin{array}{l}5(35.7 \%) \\
9(64.3 \%)\end{array}$ & $\begin{array}{c}9(39.1 \%) \\
14(60.9 \%)\end{array}$ & $\begin{array}{l}13(50 \%) \\
13(50 \%)\end{array}$ & $\begin{array}{l}27(42.9 \%) \\
36(57.1 \%)\end{array}$ \\
\hline $\begin{array}{l}\text { 9: Excluding calls to schedule an appointment, have you or someone you know ever used an } \\
\text { electronic device (phone, computer, etc.) to contact their veterinarian regarding their pet's } \\
\text { long-term care? }\end{array}$ & $\begin{array}{l}\text { Yes } \\
\text { No }\end{array}$ & $\begin{array}{c}1(6.7 \%) \\
14(93.3 \%)\end{array}$ & $\begin{array}{c}5(22.7 \%) \\
17(77.3 \%)\end{array}$ & $\begin{array}{l}10(40 \%) \\
15(60 \%)\end{array}$ & $\begin{array}{l}16(25.8 \%) \\
46(74.2 \%)\end{array}$ \\
\hline $\begin{array}{l}\text { 10: Do you feel that the use of telemedicine/telehealth could improve the long-term care of } \\
\text { your pet? }\end{array}$ & $\begin{array}{l}\text { Strongly Agree } \\
\text { Agree } \\
\text { Neutral } \\
\text { Disagree } \\
\text { Strongly Disagree }\end{array}$ & $\begin{array}{c}4(28.6 \%) \\
3(21.4 \%) \\
6(42.9 \%) \\
1(7.1 \%)\end{array}$ & $\begin{array}{c}8(36.4 \%) \\
9(40.9 \%) \\
1(4.5 \%) \\
4(18.2 \%)\end{array}$ & $\begin{array}{c}8(34.8 \%) \\
4(17.4 \%) \\
10(43.5 \%) \\
1(4.3 \%)\end{array}$ & $\begin{array}{c}12(20.3 \%) \\
15(25.4 \%) \\
25(42.4 \%) \\
3(5.1 \%) \\
4(6.8 \%)\end{array}$ \\
\hline $\begin{array}{l}\text { 11: Do you feel that the use of telemedicine could reduce the time spent waiting in the clinic } \\
\text { for long-term disease state management? }\end{array}$ & \begin{tabular}{|l} 
Strongly Agree \\
Agree \\
Neutral \\
Disagree \\
Strongly Disagree
\end{tabular} & $\begin{array}{l}2(15.4 \%) \\
6(46.2 \%) \\
5(38.5 \%)\end{array}$ & $\begin{array}{c}2(8.7 \%) \\
7(30.4 \%) \\
7(30.4 \%) \\
2(8.7 \%) \\
5(21.7 \%)\end{array}$ & $\begin{array}{c}8(32 \%) \\
9(36 \%) \\
7(28 \%) \\
1(4 \%)\end{array}$ & $\begin{array}{c}12(19.7 \%) \\
22(36.1 \%) \\
19(31.1 \%) \\
3(4.9 \%) \\
5(8.2 \%)\end{array}$ \\
\hline $\begin{array}{l}\text { 12: Do you feel that your pet's stress level would be lowered by reducing the number of } \\
\text { visits to the veterinary office for long-term disease management? }\end{array}$ & $\begin{array}{l}\text { Strongly Agree } \\
\text { Agree } \\
\text { Neutral } \\
\text { Disagree } \\
\text { Strongly Disagree } \\
\end{array}$ & $\begin{array}{l}5(38.5 \%) \\
3(23.1 \%) \\
5(38.5 \%)\end{array}$ & $\begin{array}{c}4(18.2 \%) \\
9(40.9 \%) \\
5(22.7 \%) \\
2(9.1 \%) \\
2(9.1 \%) \\
\end{array}$ & $\begin{array}{c}8(33.3 \%) \\
8(33.3 \%) \\
6(25 \%) \\
2(8.3 \%)\end{array}$ & \begin{tabular}{|c|}
$17(28.8 \%)$ \\
$20(33.9 \%)$ \\
$16(27.1 \%)$ \\
$4(6.8 \%)$ \\
$2(3.4 \%)$ \\
\end{tabular} \\
\hline $\begin{array}{l}\text { 13: If provided with proper management techniques for a disease state, how comfortable } \\
\text { would you feel monitoring and reporting the results to your veterinarian via electronic } \\
\text { communication? }\end{array}$ & $\begin{array}{l}\text { Very Comfortable } \\
\text { Comfortable } \\
\text { Neutral } \\
\text { Uncomfortable } \\
\text { Very Uncomfortable }\end{array}$ & $\begin{array}{l}2(16.7 \%) \\
4(33.3 \%) \\
6(50 \%)\end{array}$ & $\begin{array}{c}1(4.3 \%) \\
8(34.8 \%) \\
7(30.4 \%) \\
2(8.7 \%) \\
5(21.7 \%)\end{array}$ & $\begin{array}{l}7(29.2 \%) \\
8(33.3 \%) \\
7(29.2 \%) \\
2(8.3 \%)\end{array}$ & $\begin{array}{c}10(16.9 \%) \\
20(33.9 \%) \\
20(33.9 \%) \\
4(6.8 \%) \\
5(8.5 \%)\end{array}$ \\
\hline $\begin{array}{l}\text { 14: Do you feel that the use of telemedicine/telehealth to monitor and manage long-term } \\
\text { disease states would decrease the relationship you and your pet have with the } \\
\text { veterinarian? }\end{array}$ & \begin{tabular}{|l|} 
Strongly Agree \\
Agree \\
Neutral \\
Disagree \\
Strongly Disagree \\
\end{tabular} & $\begin{array}{l}4(33.3 \%) \\
8(66.7 \%)\end{array}$ & $\begin{array}{c}6(26.1 \%) \\
5(21.7 \%) \\
7(30.4 \%) \\
4(17.4 \%) \\
1(4.3 \%)\end{array}$ & $\begin{array}{l}5(20.1 \%) \\
8(33.3 \%) \\
8(33.3 \%) \\
3(12.5 \%)\end{array}$ & $\begin{array}{c}11(18.6 \%) \\
17(28.8 \%) \\
23(40 \%) \\
7(11.9 \%) \\
1(1.7 \%)\end{array}$ \\
\hline 15: Would you like for information on telemedicine/telehealth? & $\begin{array}{l}\text { Yes } \\
\text { No }\end{array}$ & $\begin{array}{c}3(21.4 \%) \\
11(78.6 \%)\end{array}$ & $\begin{array}{c}9(40.9 \%) \\
13(59.1 \%)\end{array}$ & $\begin{array}{c}5(20 \%) \\
20(80 \%)\end{array}$ & $\begin{array}{l}17(27.9 \%) \\
44(72.1 \%) \\
\end{array}$ \\
\hline
\end{tabular}




\section{Appendix B}

\section{Figure 1. Review of Literature Search Results}
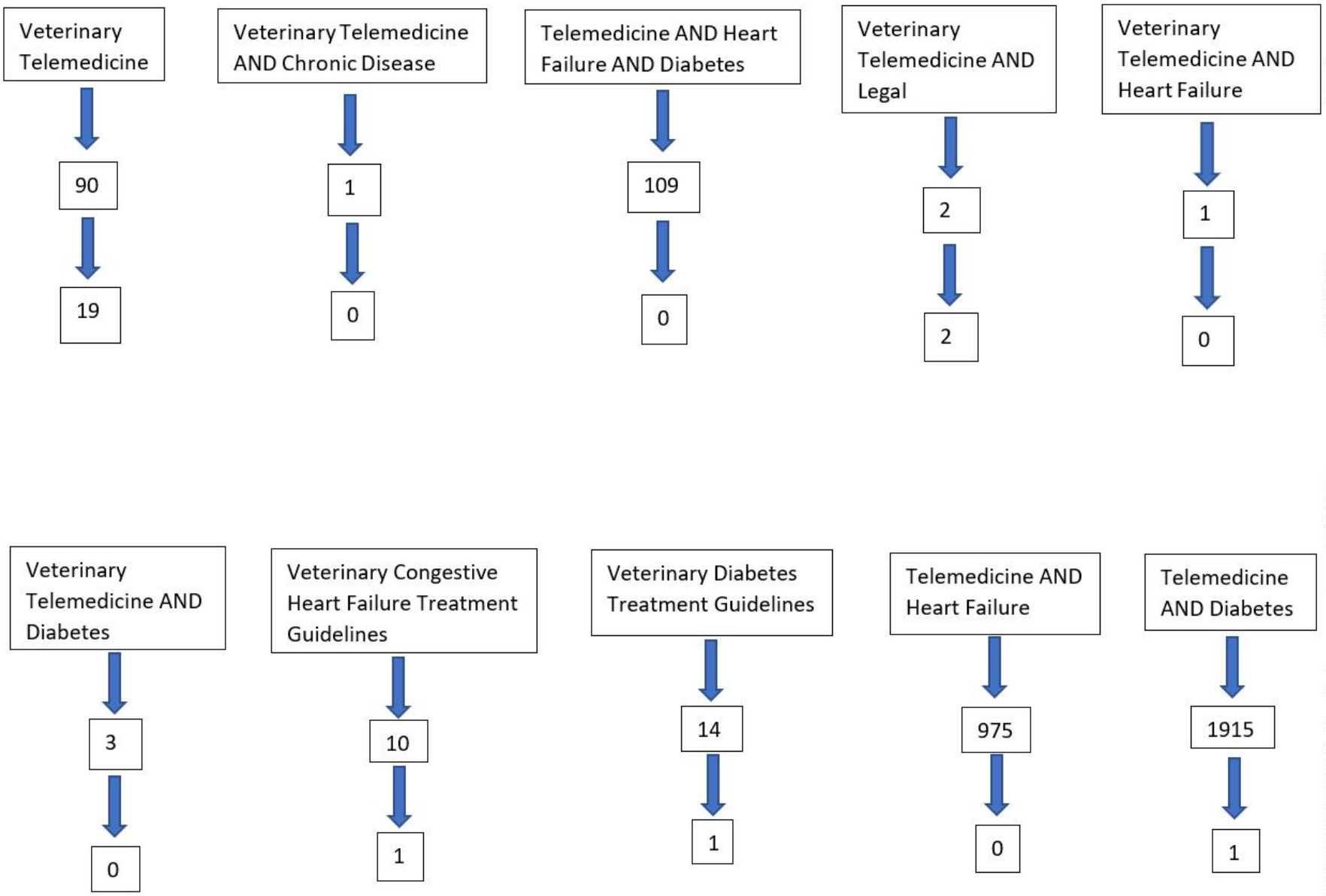
Figure 2. Sample IRB Approved Consent Cover Letter

IRB NUMBER: 19-06766-XM

IRB APPROVAL DATE: 08/27/2019

\section{Survey of Client Perspective On The Use of Veterinary Telemedicine For Chronic Disease Management}

You have volunteered to participate in a research survey that is aimed to determine personal views on the utilization of telemedicine/telehealth for chronic disease state management of your pets. Individuals being asked to participate in this survey reside in East Tennessee and within a rural area. Individuals asked to participate in this survey should be over 18 years of age and have a current pet they care for on a regular basis.

If you have any questions regarding this research survey you may contact the Principal Investigator, Nathan Matlock, at 865-236-1489.

This survey is designed to determine what your personal opinions are about the use of electronic devices to manage your pet's current or possible future chronic disease state management.

This survey is composed of a series of questions and should take the participant approximately 10-15 minutes to complete the questionnaire. Participation in this survey carries no foreseeable risks.

This survey alone will likely not provide any direct benefit to the patient or society currently. This survey is designed to help gauge the current view on the use of telemedicine in a pet's chronic disease state management. Your participation in this survey study is voluntary and if you choose to not participate or to stop participating at any time, your decision will not result in a penalty or affect your rights.

The survey questionnaire that you are completing today will not contain any identifying information and once the data from the sheets have been collected the sheets will be destroyed.

You may contact Cameron Barclay, MSA, UTHSC IRB Director, at 901-448-4824, or visit the IRB website at http://www.uthsc.edu/research/compliance/irb/ if you have any questions about your rights as a research subject, or if you have questions, concerns, or complaints about the research. 


\section{Figure 3. IRB Approved Survey Form Sample}

IRB NUMBER: $19-06766-X M$

IRE APPRONAL. DATE: 08/27/2019

Questions for Survey

1. Are you male, female, or identify as other?
a. Male
b. Female
c. Other

2. Age
a. Under 23
b. 24-42
c. $43-54$
d. 55-73
e. Over 74

3. Do you have regular access to the internet?
a. Yes
b. No

4. Do you or someone you know have an animal that requires management of a chronic disease state (e.g. Diabetes or Heart Failure)?
a. Yes
b. No

5. If so, what disease state are they being treated for?
a. Diabetes
b. Congestive Heart Failure
c. Other - Please list:

6. How long has your pet been treated for their long-term disease state?
a. Less than 1 year
b. 1.5 years
c. Greater than 5 years
d. N/A

7. Are your pet(s) with long-term disease(s) seen regularly by a veterinarian to manage their longterm disease?

a. Yes - regular management - CKD, DM, CHF, Thyroid - every 6 months

b. No - only when disease state flares

8. Are you aware of what telemedicine/telehealth is?

a. Yes

b. No

9. Excluding calls to schedule an appointment, have you or someone you know ever used an electronic device (phone, computer, etc.) to contact their veterinarian regarding their pet's longterm care?
a. Yes

b. No

10. Do you feel that the use of telemedicine/telehealth could improve the long-term care of your pet?
a. Strongly agree
b. Agree
c. Neutral 
Figure 4. Gender Distribution

\section{Gender Distribution}

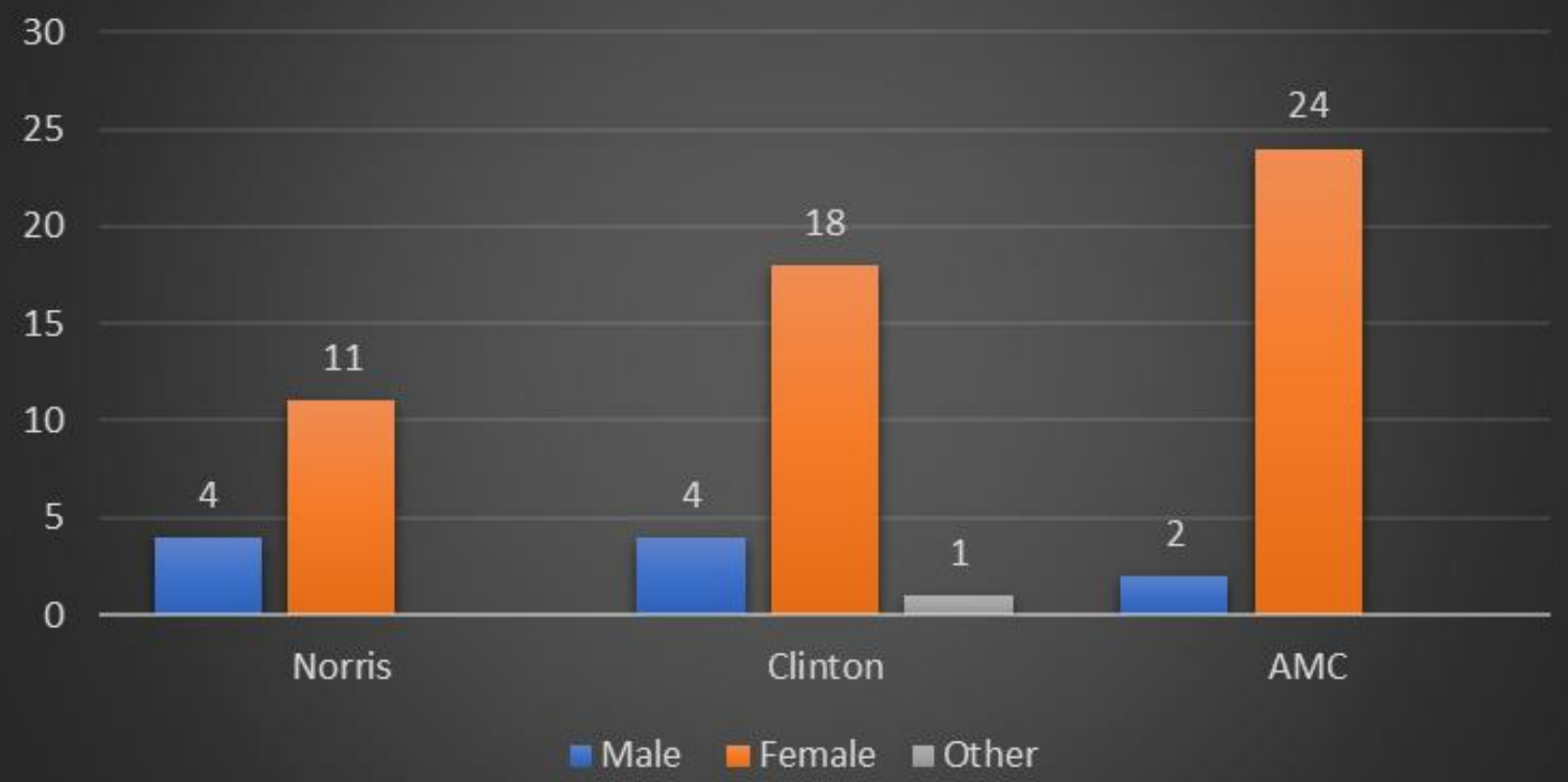

Figure 5. Age Distribution

\section{Age Distribution}

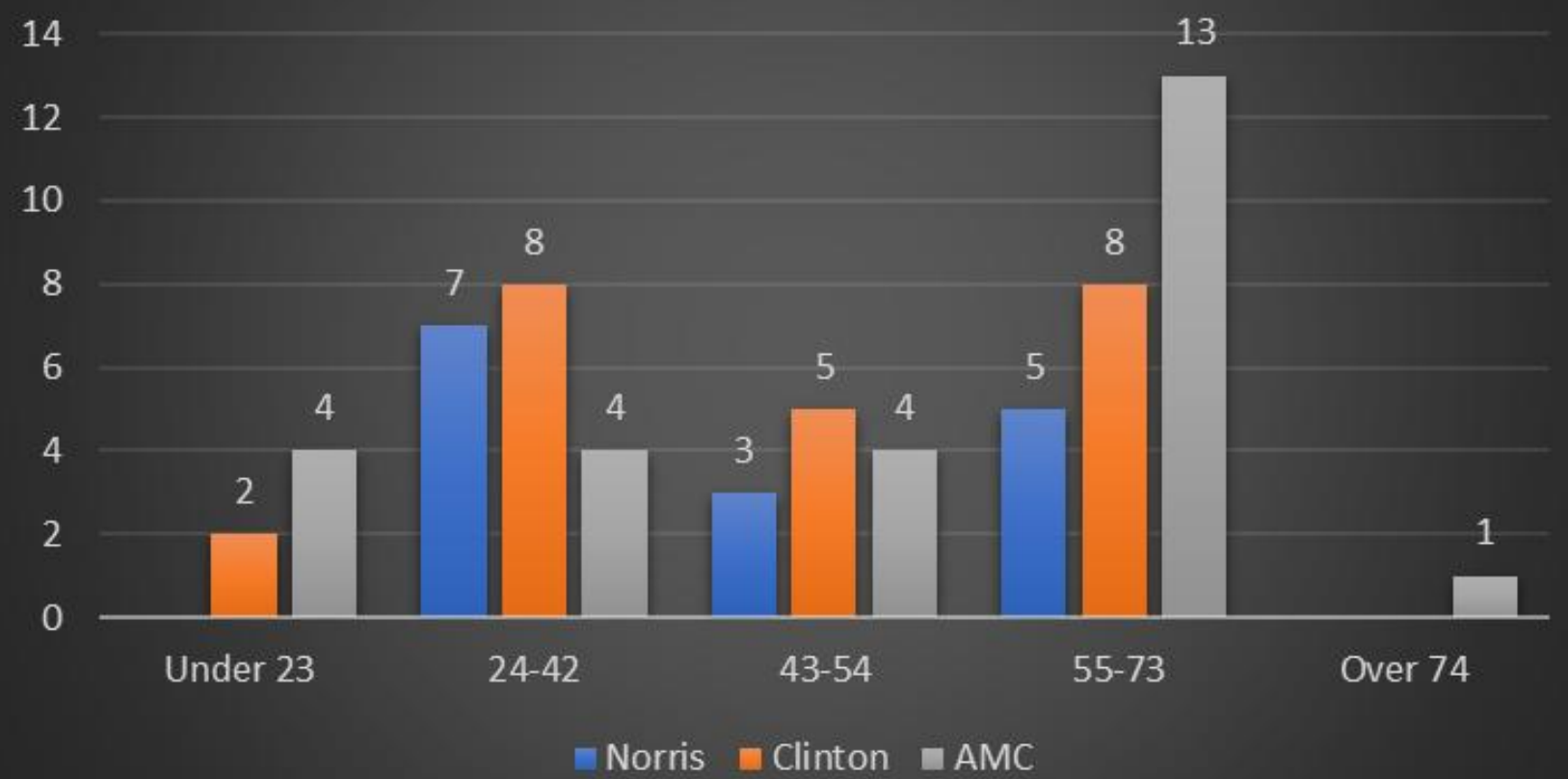


Figure 6. Clients with Accessible Internet Connection

\section{Clients with Accessible Internet Connection}

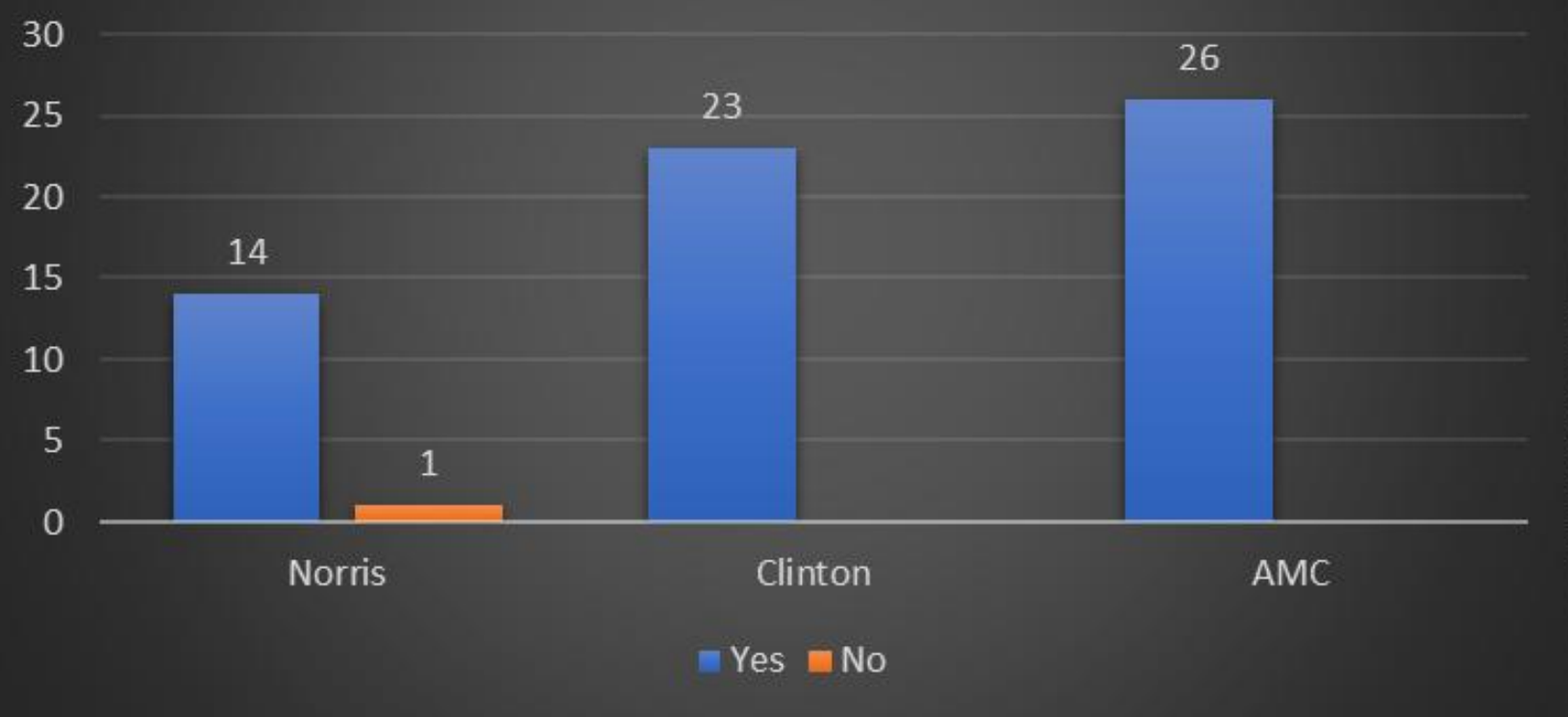

Figure 7. Active Chronic Disease State Management

\section{Active Chronic Disease State Management}

20

19

15

12

10

5

4

4

0

Norris

Clinton

AMC 
Figure 8. Current Duration of Chronic Disease State Management

\section{Current Duration of Chronic Disease State Management}

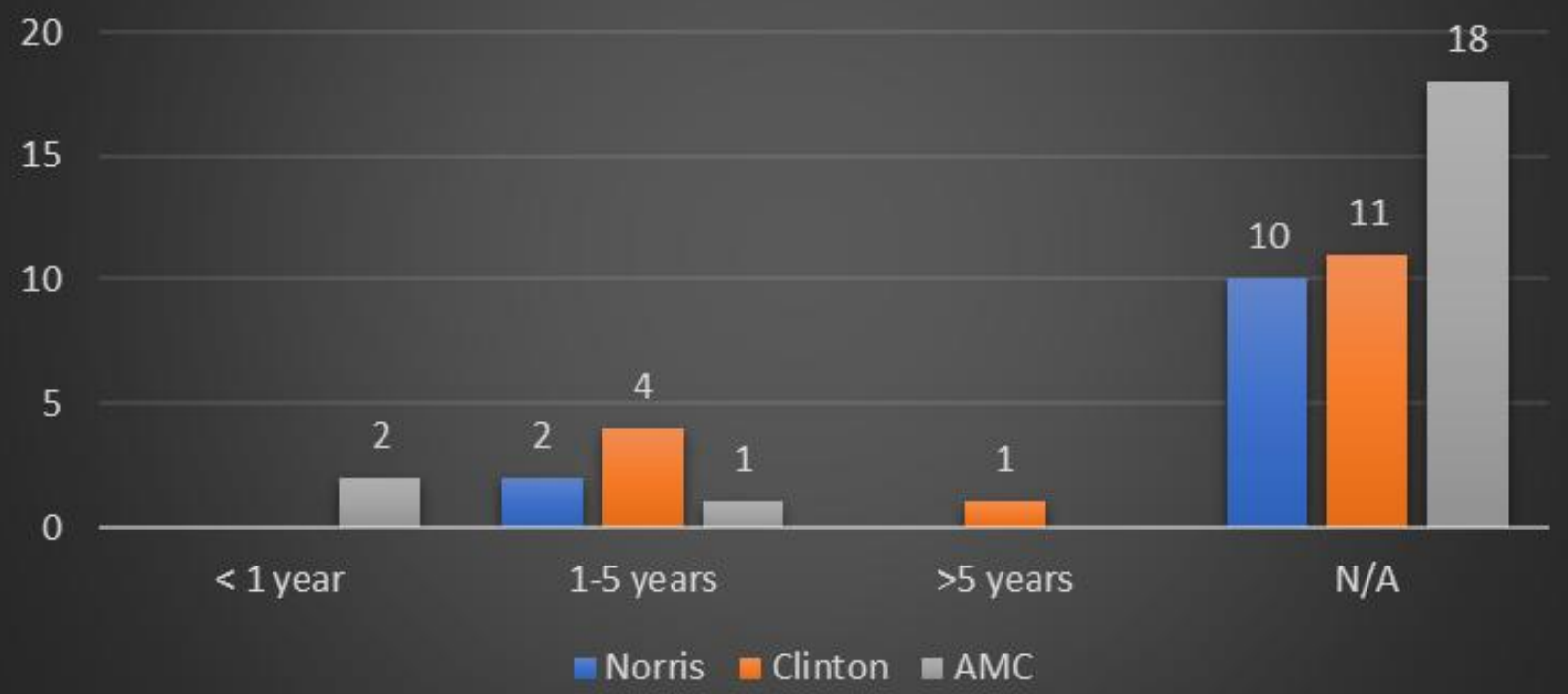

Figure 9. Aware of What Telemedicine Is?

\section{Aware of What Telemedicine Is?}

16

14

12

10

8

6

4

2

0

\section{4}

13

13

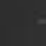

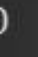

9

9

$=$

6

5

Norris

Clinton

AMC 
Figure 10. Would Telemedicine Reduce Time Spent in Clinic?

\section{Would Telemedicine Reduce Time Spent in Clinic?}

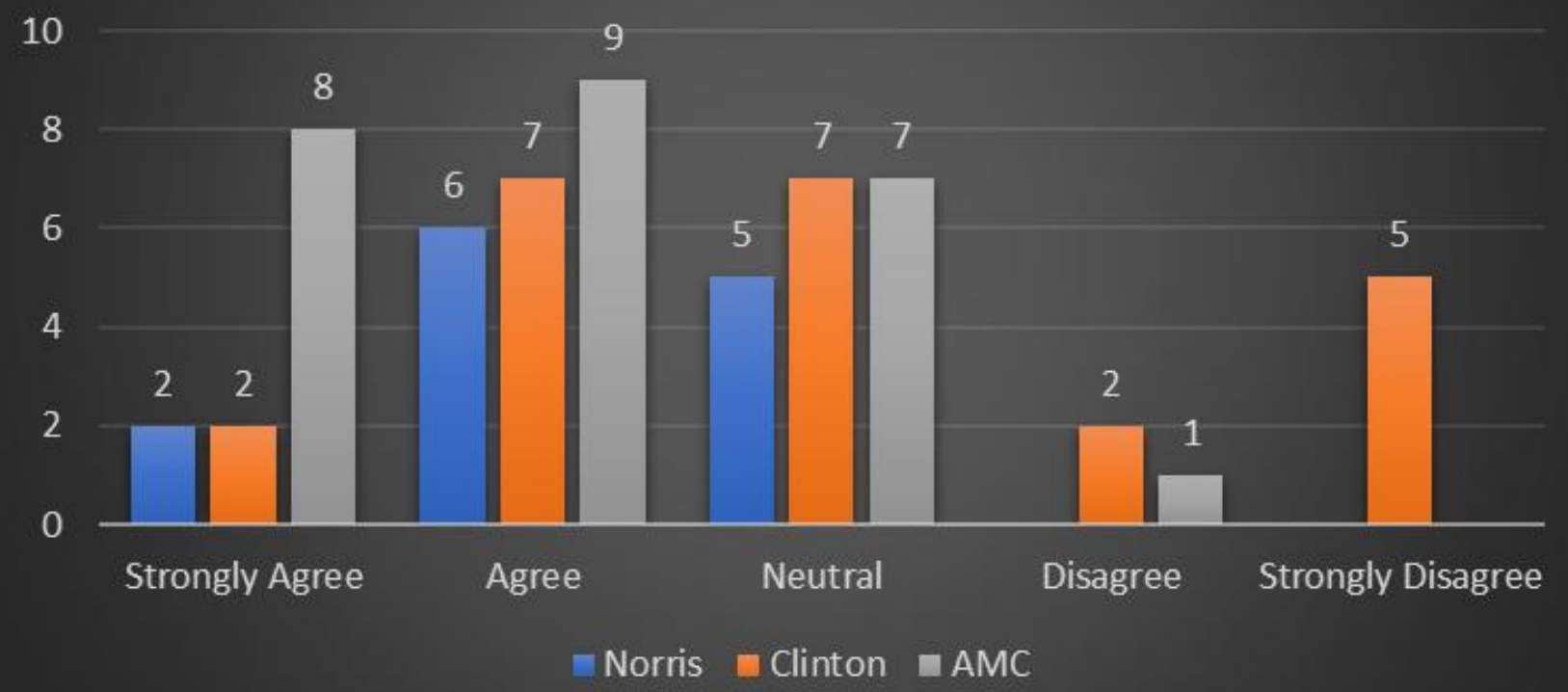

Figure 11. Would telemedicine Increase Improvement of Chronic Disease State Management?

\section{Would Telemedicine Increase Improvment of Chronic Disease State Management?}

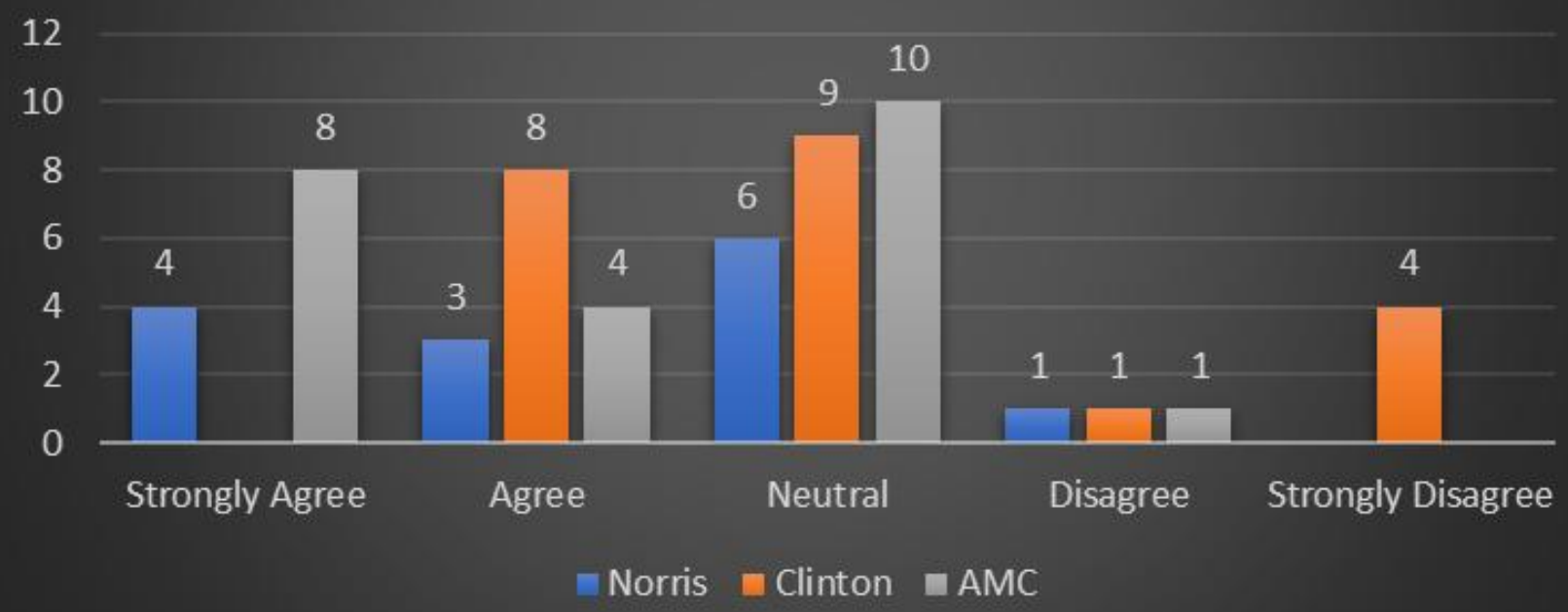


Figure 12. Would Telemedicine Reduce Pet Stress Level?

\section{Would Telemedicine Reduce Pet Stress Level?}

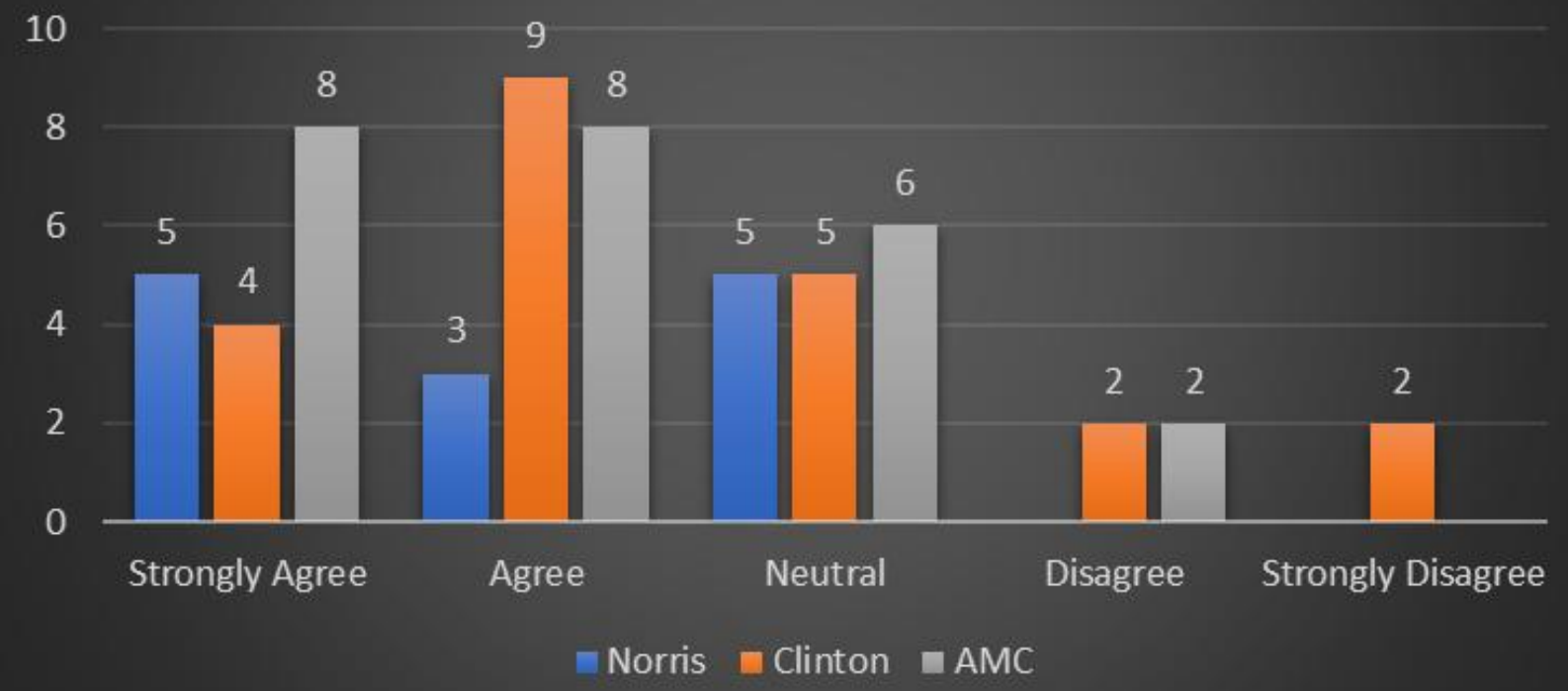

Figure 13. Comfort in Performing Self-Management of Chronic Disease State

\section{Comfort in Performing Self- Management of Chronic Disease State}

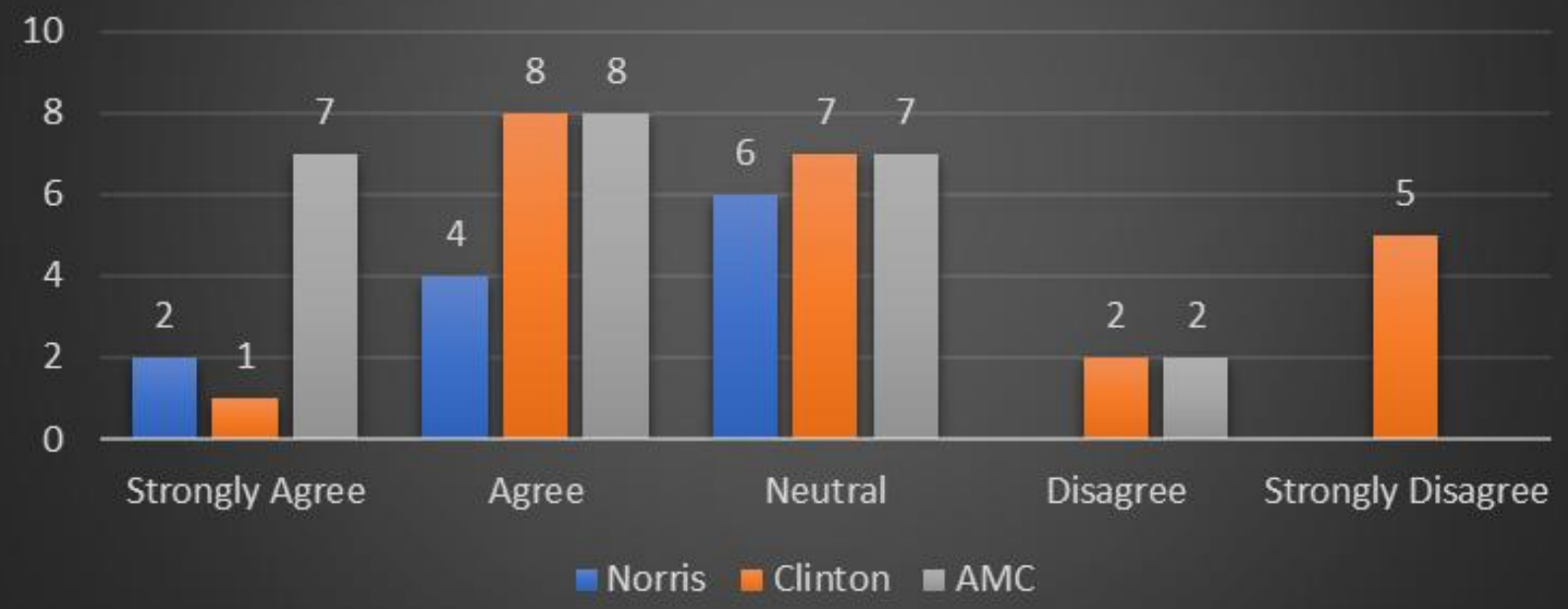


Figure 14. Does Telemedicine Reduce Relationship Between Client and Veterinarian?

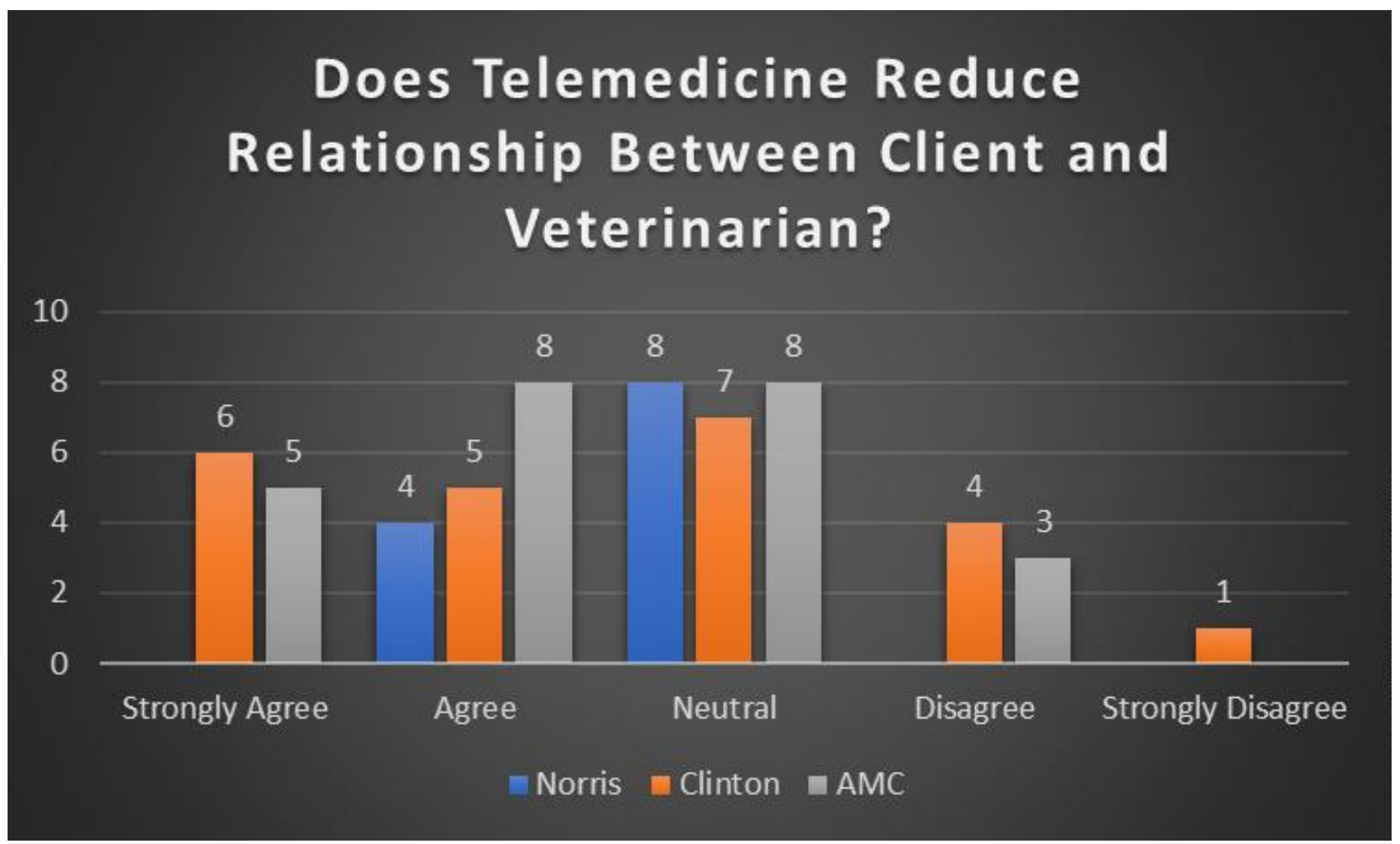

